\title{
Butler freshmen hunt for library treasure
}

\author{
By Sheridan Stormes
}

\section{One way to get students into the library early}

$\mathbf{T}$ he libraries at Butler University in Indianapolis have found a unique and fun way to get incoming freshmen into the campus libraries even BEFORE the first week of classes! They hold a library "Treasure Hunt" during freshman orientation week. This year marked the second annual such "Hunt." It was co-sponsored by the libraries and the Campus Interfraternity Council.

The Treasure Hunt is set up much like a traditional scavenger hunt. It is scheduled for a two- to four-hour time block usually on the Friday of orientation and at a time when there are few conflicting events. The actual hunt only takes about 30 minutes. Students entering the main library are greeted by librarians and student assistants who welcome them and give them a "Hunt Protocol" containing instructions on how to proceed. The next stop allows students to get their ID cards barcoded so that they will be ready to check out materials from the Butler Libraries when they come on future visits.

After receiving the obligatory barcode, the students are given a "clue" - written in the form of a limerick - that, when deciphered, tells the eager "hunters" where to find their next clue. The clues are designed in such a way as to lead the students to all of the various departments of the libraries: the online catalog (students must actually perform a search on the catalog to receive their next clue at this station), the stacks, reference, rare books and special collections, the music division, current journals room, microform reading room, curriculum resource center, interlibrary loan, reserves and circulation, and the Science Library. At each "station," the students are greeted by a regular member of the library staff. Each library staff person gives a brief (no more than five minutes) talk about the area to which the students have come. This way, the students not only become familiar with the libraries and their services but they get to know the library staff members as well. Those students who successfully complete the "Hunt" are given a prize. Prizes range from $\$ 1$ worth of free photocopying to coupons for free pizzas, movie passes, and various items bearing the university logo, such as key rings, notebooks, bumper stickers, frisbees, beverage mugs, and even a "deluxe" Butler bulletin board.

... the students not only become familiar with the libraries and their services but they get to know the library staff members as well.

\section{Getting the word out}

Advertising for the Library Treasure Hunt is done in a number of ways. A colorful flyer (on day-glo construction paper) is included in each freshman packet. More flyers are posted on bulletin boards in residence halls and in all the academic buildings. A giant banner announcing the hunt is hung across the front of the main library during orientation week. Finally, faculty and student orientation guides and members of the various fraternities and sororities are encouraged to "spread the word" about the hunt to the incoming students. 
Some funds for prizes are set aside from the regular library budget. Other prizes are obtained through phone, letter, and direct personal solicitations. Students from the Inter-fraternity Council were especially helpful with publicity and in soliciting prizes. A few students worked side by side with the library staff in greeting the "Huntspeople" and distributing the prizes.

Approximately 100 students participated in each of the two Hunts held so far. This represents ap-

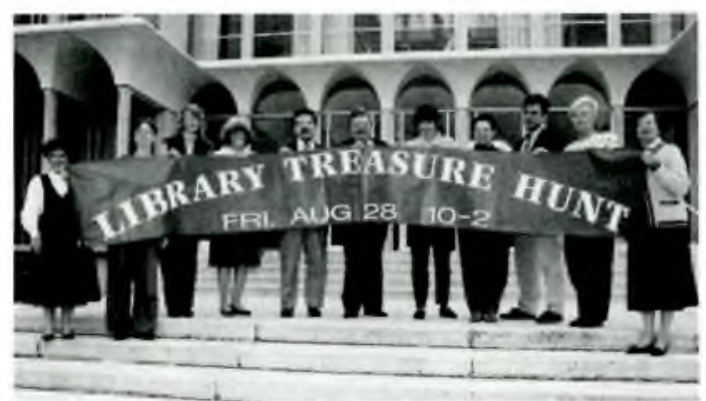

Library staff holding the banner used to publicize the treasure hunt. ule. Past schedules only indicated the time block during which participation was possible. This may have led some students to believe that the hunt itself took four hours to complete, thus discouraging some otherwise inter- proximately one-sixth of the total number in the freshman class for these two years. The staff intend to make a few modifications next year to improve participation. One will be to limit the time period during which students may participate in the hunt to two hours (tather than four). Another anticipated change is to make sure that the time necessary to complete the hunt is stated in the freshman orientation sched- ested people. Finally, next year, the library plans to aim for even greater distribution of flyers and, also, to have some larger posters printed up advertising the hunt.

Thus far, the hunt idea appears to have been a "hit" with the students who have participated. During this past hunt, a few of the participants were actually overheard declaring, "Gosh, this is the most fun we've had all week!"

For more information about this project, please contact Sheri Stormes, associate direc tor for public services, Irwin Library, Butler University, 4600 Sunset Ave., Indianapolis, IN 46208.

\section{Attention Libraries!}

Need hard copies from MICRO-OPAQUE CARDS?

We can supply this service for you, your faculty, or your students.

The total cost of $\$ 5$ includes the first 10 pages 25 cents a page thereafter.

We copy from our collection or your card.

For more information or to order, write or call

Kim Daugherty

MU Libraries

115 Ellis Library

Columbia, Mo. 65201-5149

Phone (314) 882-3398

Fax [314] 884=5004 ELLSCOPY@MIZZOU1

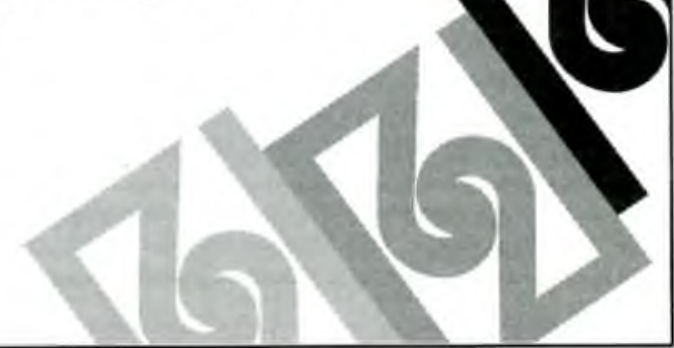

